\title{
Trypanosomosis in a Sambar Deer
}

\author{
"Faez Firdaus Jesse Abdullah", ${ }^{1,3}$, Konto Mohammed ${ }^{1,5}$, Muhammad Syafiq bin \\ Shahudin ${ }^{1}$, Lawan Adamu ${ }^{1,5}$, Abdinasir Yusuf Osman ${ }^{1,2}$, Yusuf Abba ${ }^{2,5}$, \\ Abdulnasir Tijjani ${ }^{2,5}$, Noorashimah Roslim ${ }^{4}$, Dayang Norhaizam Awang ${ }^{4}$, \\ Abdul Aziz Saharee ${ }^{1}$, Mohammed Zamri Saad ${ }^{2}$, Abdul Wahid Haron ${ }^{1,2}$ \\ ${ }^{1}$ Department of Veterinary Clinical Studies; ${ }^{2}$ Department of Veterinary Pathology and Microbiology; ${ }^{3}$ Research \\ Centre for Ruminant Disease, ${ }^{4}$ University Veterinary Hospital, Faculty of Veterinary Medicine, Universiti Putra \\ Malaysia, 43400 UPM Serdang, Selangor, Malaysia; ${ }^{5}$ Faculty of Veterinary Medicine, University of Maiduguri, \\ PMB 1069, Borno State, Nigeria.
}

\begin{abstract}
A five years old Sambar deer was presented to the University Veterinary Hospital of Universiti Putra Malaysia. The deer was physically diagnosed with clinical signs of depression, lethargy, teeth grinding, pallor of mucous membranes, the vital parameters showed pyrexia $\left(40.9^{\circ} \mathrm{C}\right)$, increase in pulse (197beats/min.) and respiratory rates (42 circles/min.). Laboratory examination of the Buffy coat by micro haematocrit centrifugation technique revealed the presence of motile flagellates. Buffy coat smear examination confirmed the presence of Trypanosome spp. The disease was diagnosed based on clinical signs and laboratory finding. Diminazene Aceturate at a dose rate of $3.5 \mathrm{mg} / \mathrm{kg}$ bodyweight was administered intramuscularly, coupled with multivitamin and fluid therapy proves effective in treating the condition. This report shows the significance of wild ruminants in maintaining the transmission cycle of this parasite and timely treatment could resolve the disease condition.
\end{abstract}

Keywords: Sambar deer, Trypanosomosis, clinical signs, Diminazene Aceturate.

\section{Introduction}

The Sambar deer, classified as Rusa unicolor, is the largest oriental deer found in Asia. It is an herbivorous wild ruminant that browses on a wide variety of plant species, allowing it to have variable habitat flexibility and serving as a good medicinal source of diet to locals (Leslie, 2011). They are year round breeders, but usually considered as seasonal breeders, because breeding usually peaks seasonally (Geist, 1998).

There has been a considerable decline in Sambar deer population in recent years. This threat was brought about as a result of conservation challenges like over exploitation of its meat and antlers for traditional medicine, commercial purposes and disease agents like Trypanosomes (IUCN Redlist, 2011).Trypanosomosis is an acute/chronic form of disease caused by protozoan parasites of the genus Trypanosoma, affecting both ruminants and non-ruminants. The parasites are characterised by the presence of flagellum and a kinetoplast which is either terminal, sub terminal or marginal, depending on the specie. Transmission is by the bite of infected dipterous flies (e.g.: Tabanus, Stomoxys, Chrysops) and Vampire Bats (Nurlaini, 2007).

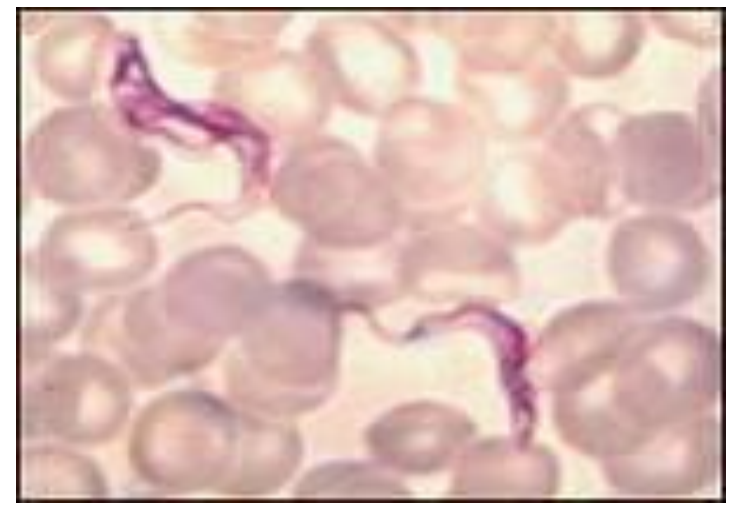

Fig. 1: photomicrograph of T. evansi after Buffy coat smear with Giemsa’s stain (x100). 


\section{Case History}

A five years old male Sambar deer, weighing 80kg with body condition score of $3 / 5$ was presented to the large animal ward for examination with the complain of weakness, inactivity and inappetence. The animal is managed under captivity mimicking the wild.

Physical examination revealed weakness, emaciation, pallor of mucous membranes of the mouth and eyelids and teeth grinding with multiple localized patchy alopecic regions along entire dorsum which appeared dry and flaking. The vital parameters showed fever $\left(40.9^{\circ} \mathrm{C}\right)$, increase in pulse and respiratory rates of 197 beats/min and 42 circles/min respectively.

\section{Diagnosis}

Tentatively, the condition was diagnosed to be that of haemoparasitosis and blood sample was taken for parasitological and haematological examination.

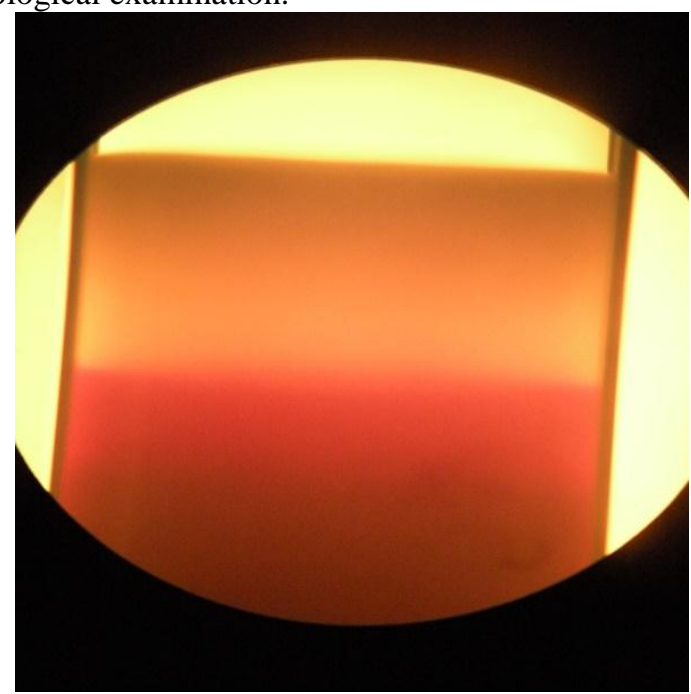

Fig 2: Haematocrit capillary tube showing the serum, Buffy coat and plasma after centrifugation (x10).

\begin{tabular}{lcc}
\hline Parameter & value & Ref. value \\
& \multicolumn{2}{c}{} \\
\hline Temperature & $40.9^{0} \mathrm{C}$ & $38.0-39.4$ \\
Respiratory rate & $42 \mathrm{c} / \mathrm{min}$ & $22-34$ \\
Pulse rate & $149 \mathrm{~B} / \mathrm{min}$ & $65-94$ \\
PCV & 0.23 & $0.42-0.55$ \\
MCV & 41 & $53-77$ \\
\end{tabular}

Table 1: showing the vital parameters.

Examination of the Buffy coat by micro haematocrit centrifugation technique revealed the presence of motile flagellates. Buffy coat smear examination confirmed the presence of Trypanosome spp. Furthermore, examination of thin and thick film smears does not reveal the presence of any other haemoparasites. Haematological parameters revealed low PCV indicates anaemia. RBC parameters revealed microcytic normochromic anaemia suggestive of iron deficiency anaemia due to chronic blood loss. There was lymphocytosis due to parasitic infection.

Treatment: A single deep intramuscular injection of Diminazene Aceturate at a dose rate of $3.5 \mathrm{mg} / \mathrm{kg}$ body weight was administered as an antiprotozoal agent yielded a positive result in clearing the blood for parasitaemia. Other supportive therapies administered were Pyroxicam injection (Pauxicam ${ }^{\mathrm{R}}$ ) at a dose rate of $10 \mathrm{mg} / \mathrm{kg}$ body weight intramuscularly, for 3 days. Multi-vitamin $\left(\right.$ Multinor $^{\mathrm{R}}$ ) injection was administered at the dose rate of $10 \mathrm{mg} / \mathrm{kg}$ body weight, for 5 days and fluid therapy ( $5 \%$ dextrose) to expand the blood volume. The deer responded well to the treatment.

\section{Discussion}

Trypanosomosis is considered endemic to South-east Asia where the disease is common to cattle and buffaloes. Even though, deer are susceptible to Trypanosomosis, reports of the disease in deer are not common in Malaysia, until recently. However, Adrian et al., (2010) and Nurlaini et al., (2013) reported the presence of the parasite in the blood of some Timorensis deer from some farms in Malaysia. 
The increase in host range from domestic to wild ungulates as a result of the parasite's vector diversity and feeding habit of the said vectors (Tabanus and Stomoxys). Thus, this report showed the dynamics of the disease among ruminant animals and a change in the course of the disease from chronic to acute resulting in a great economic loss. Hence there is the urgent need to address this situation, as deer has been domesticated by man in recent years for recreational and other purposes. All cases of Trypanosomosis must be diagnosed and treated promptly in the farms as this disease needs early intervention to save the animal.

\section{Acknowledgement}

The authors would like to acknowledge the efforts of the entire staff of the Large Animal Ward of the University Veterinary Hospital. Our special thanks to Mohammed Jefri Norsidin for his tireless effort in managing the case.

Conflict of interest: no competing interest declared.

\section{References}

[1]. Adrian, M.S., Rehana, A.S., Latiffa, H. and Wong, M.T. (2010). Outbreak of Trypanosomosis and the seroprevalence of T.evansïn deer breeding Centre in Perak, Malaysia. Trop. Anim. Health Prod. 42: 145-150.

[2]. Geist, V. (1998). Deer of the world: there evolution, behavior and ecology. Stackpole Books, Mechanicsburg, Pennsylvania.

[3]. IUCN Red list (November 2011). http://www.iucnredlist.org/

[4]. Leslie Jr, D.M. (2011). Russa unicolor (Artiodactyla: Cevidae). Mammalian species, 43(871): 1-30

[5]. Nurulaini R., Jamnah O., Adnan M., Zaini C.M.,Khadijah S., Rafiah A. \&Chandrawathani P. (2007).Mortality of domesticated java deer attributed to surra(2007).

[6]. Nurulaini, R., Premaalatha, B., Zaini, C.M., Adnan, M., Chandrawathani, P., Fazly Ann, Z.A., Enie, A.A. and Ramlan, M. (2013). Trypanosomiasis outbreak in deer, cattle, buffaloes and pigs in Perak. Malaysian Journal of Vet. Res. 4(1): 55-58. 